\title{
3-D FE-Modelling of a mass movement on basis of geophysical investigations
}

\author{
E. Castillo *), F. Kohlbeck*) \\ *) Technical University Vienna, Dept. of Geophysics, Vienna, Austria
}

\section{ABSTRACT}

A landslide has been modeled by three different models utilizing the FE-Program BMINES. The combination of several geophysical methods provided the information about the 3D-geometry of the slip and the range of some material properties. Seismic refraction surveys, geoelectrical soundings and electromagnetic measurements have been used for the characterization of the slip, location; depth, and physical properties of material.

Several geodetic surveys, completed within two years, were performed to measure the displacements on the slope. The resulting set of displacement vectors has been used to estimate the accuracy of each FE-Model by comparing the calculated displacements and the measured displacements on the slope.

The elevations measured on the surface and the depths to the sliding surface obtained from the seismic refraction lines were interpolated on a regular grid with side dimensions of $20 \mathrm{~m}$ (Fig. 2). The bottom of the FE-Models was a plane.

\section{SITE CHARACTERISTICS}

The landslide behind the "Bärenwirt" restaurant is located at the Haidbachgraben near the Semmering pass, a mountainous region on the NE side of the Austrian Alps (Fig. 1). The size of the slope is about $400 \mathrm{~m} \times 300 \mathrm{~m}$ with a maximum difference in height of $80 \mathrm{~m}$ (Fig. 2). Movements on this landslide have been observed over many years, but they were not measured or recorded. The geology of this site is characterized by soil and strongly unconsolidated variegated schists ("Bunter-Keuper", Upper Triassic) with high contents of muscovite and quartz and low contents of montmorillonite; it is underlain by limestone, interspaced with thick gypsum lenses. The schist has a low permeability and cohesion values between $5.0 \mathrm{~N} / \mathrm{cm}^{2}$ and $5.25 \mathrm{~N} / \mathrm{cm}^{2}$.

\section{DATA ACQUISTTION}

For the geodetic survey a theodolite with an automatic distance-meter was used. Eight fixed datum points and 30 measured points were used to detect displacements on the slip surface.

Data from seismic refraction lines of a combined length of approximately $850 \mathrm{~m}$ were collected along three traverses parallel to the strike, and two traverses parallel to the direction of dip. Geophone spacings of $10 \mathrm{~m}$ and $5 \mathrm{~m}$ were used. One short profile was acquired two times, in different seasons, to observe the variation of the p-wave-velocity. The Seismic energy was generated by hammer blows or by a seisgun. The end shots and the offset shots for the short profiles were made with a seisgun with $8 "$ and $12 "$ shells, at a depth of $0.5 \mathrm{~m}$ to $1.5 \mathrm{~m}$.

Two vertical electric soundings (VES) were made with a Schlumberger arrangement at two locations along different refraction lines(Fig. 2). The maximum separation of the current electrodes was $240 \mathrm{~m}(\mathrm{AB} / 2=120 \mathrm{~m})$. 
Electromagnetic (EM34 horizontal dipol) induction surveys were conducted with $10 \mathrm{~m}$ and $20 \mathrm{~m}$ coil distance at serveral sites to delineate the boundaries of the landslide.

\section{DATA ANALYSIS}

The seismic refraction data analysis was carried out using the Generalized Reciprocal Method of Palmer(1980). Figure 3 shows the thickness and aproximate velocity for each identifiable layer in the line S3; a three-layer model was used. The identification of the types of material was based on the calculated velocities. The main problem of the modelling process is the recognition of the sliding surface. The top layer is soil with a velocity of $400 \mathrm{~m} / \mathrm{s}$. It is followed by a layer with an average velocity of $1100 \mathrm{~m} / \mathrm{s}$ (slide mass) and by the base material, with a velocity range of 3100 to $3300 \mathrm{~m} / \mathrm{s}$ corresponding to fractured and weathered bedrock. The VES were interpreted using the software RESLXP and the Zohdy method (Zohdy, 1989). The unconsolidated schist is represented by a resistivity of $400 \Omega \mathrm{m}-450 \Omega \mathrm{m}$ and the bedrock by a moderate resistivity of $90 \Omega \mathrm{m}-100 \Omega \mathrm{m}$ (Fig.3).

The geological mapping and the analysis of different EM lines have been jointly used to delineate two boundaries (Fig. 5 and Fig. 6), the outward line bounds the slip area and the internal line bounds a zone with big displacements.

The measured elevations and the interpreted depths were interpolated by kriging to obtain a 3D FE-Net (Fig. 4). The velocity model was used to limit the variation of elastic parameters.Three different FE-models were tested; "Elastic, isotropic, constant modulus, with slip elements", "Perfectly plastic, polynomial yied surface, constant modulus" and "viscoplastic on rigid ground". The calculated displacements for each model have been compared with that measured on the slope.

\section{RESULTS}

The viscoplastic FE-model results(Fig. 5 and Fig. 6) matched the measured and interpolated displacements better than the other two models. The form of the sliding surface differs with the theoretical plane used by stability analyse in 2D methods. The 3D FE-Method was applied to estimate the volume and the slip direction of the landslide. Additional information about the correct mechanism of the model was obtained, which is a step forward in the prediction of time of the movement. The method permits a satisfactory model verification, additional models could be constructed to simulate the effects of materials and geometrical aspects of landslides. The prediction of the movement is a more complex problem and can only be solved by further observations that include the climate influence, especially the connection of the precipitation with the ground water flow.

\section{REFERENCES}

Palmer, D., 1980, The Generalized Reciprocal Method of Seismic Refraction Interpretation, Ed . Kenneth B.S. Burke, 93 pp.

Zohdy,A.A., 1989, A new method for the automatic interpretation of Schlumberger and wenner sounding curves, Geophysics, vol. 54, No.2., pp. 245-253. 


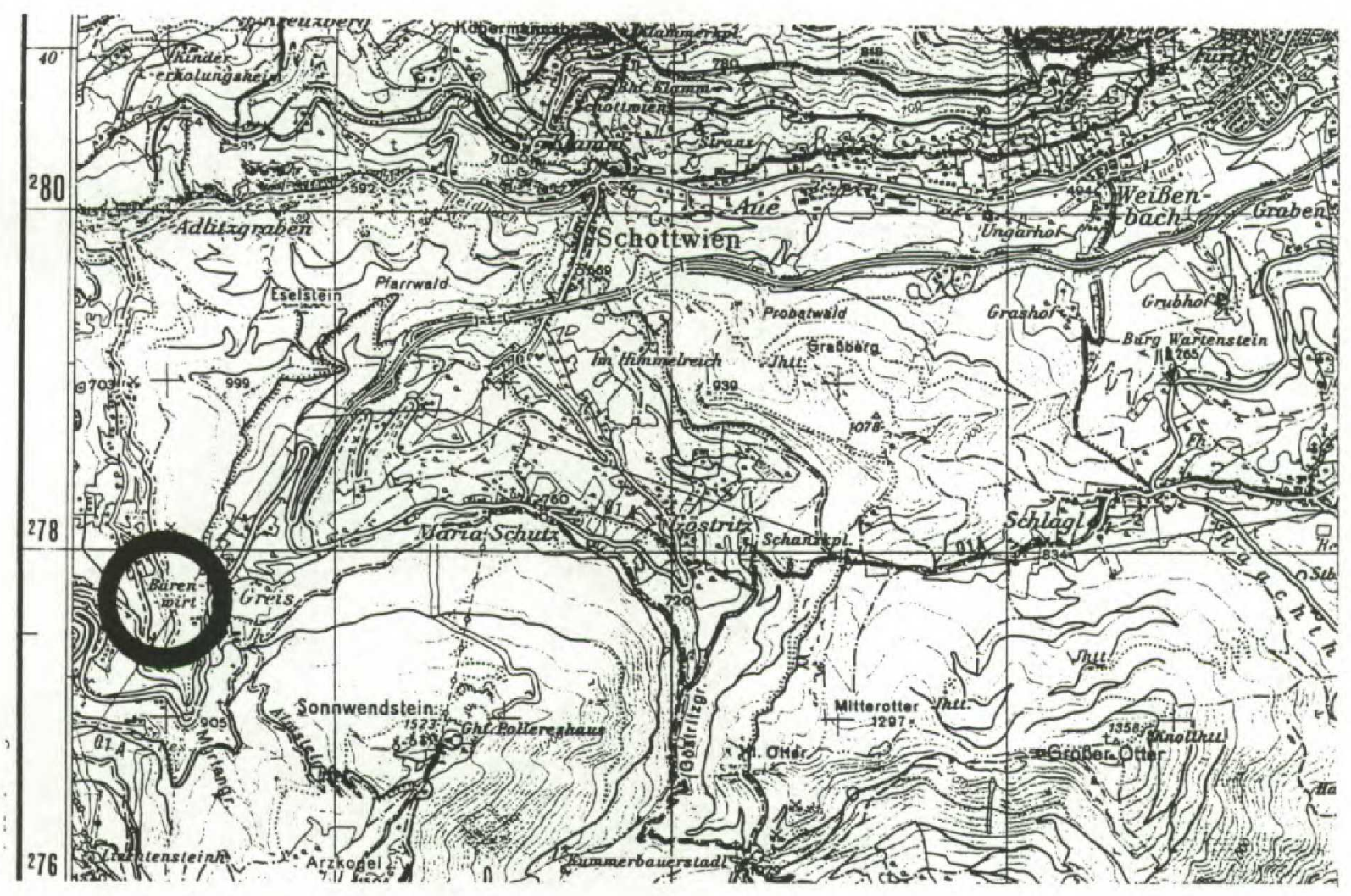

Figure 1. Location of study area

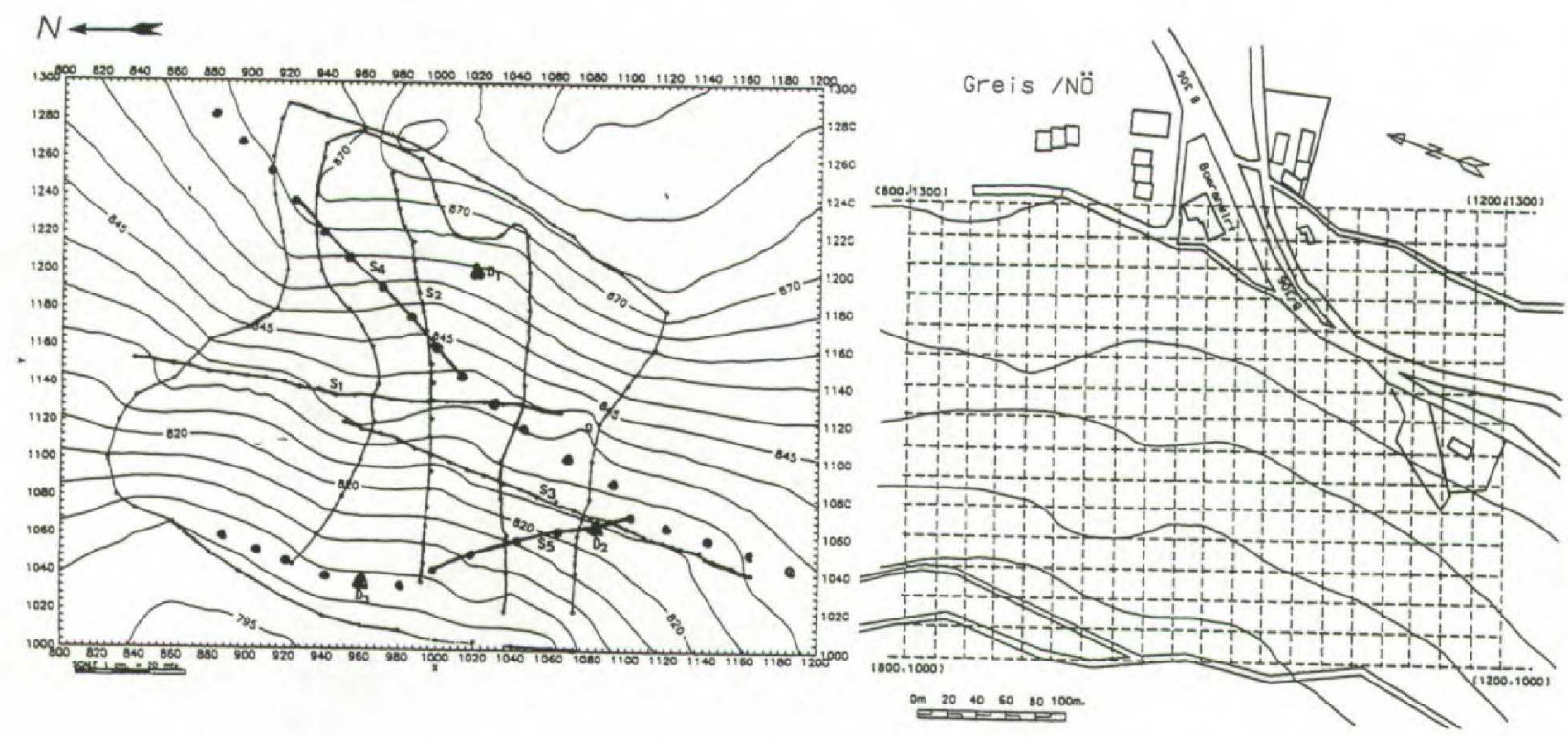

Figure 2. Interpolated grid and geophysical measurements. 


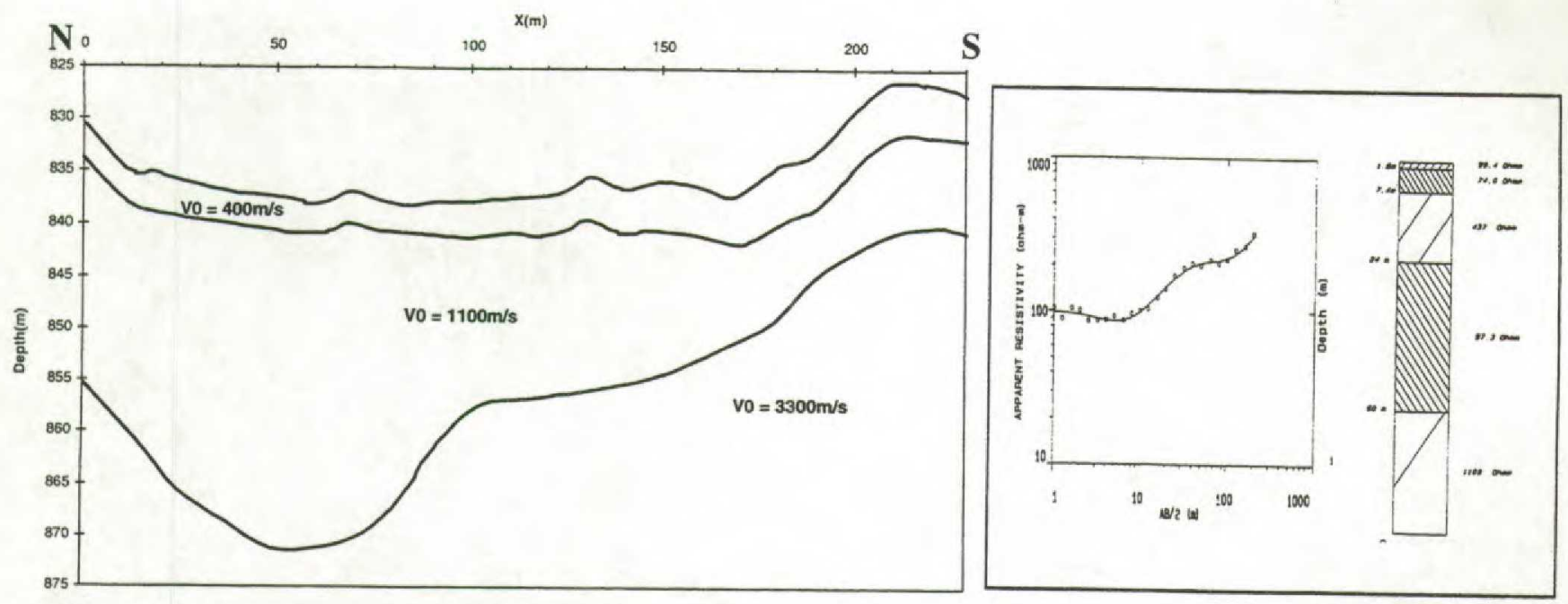

Figure 3. Seismic refraction line S3 and geoelectrical sounding D2

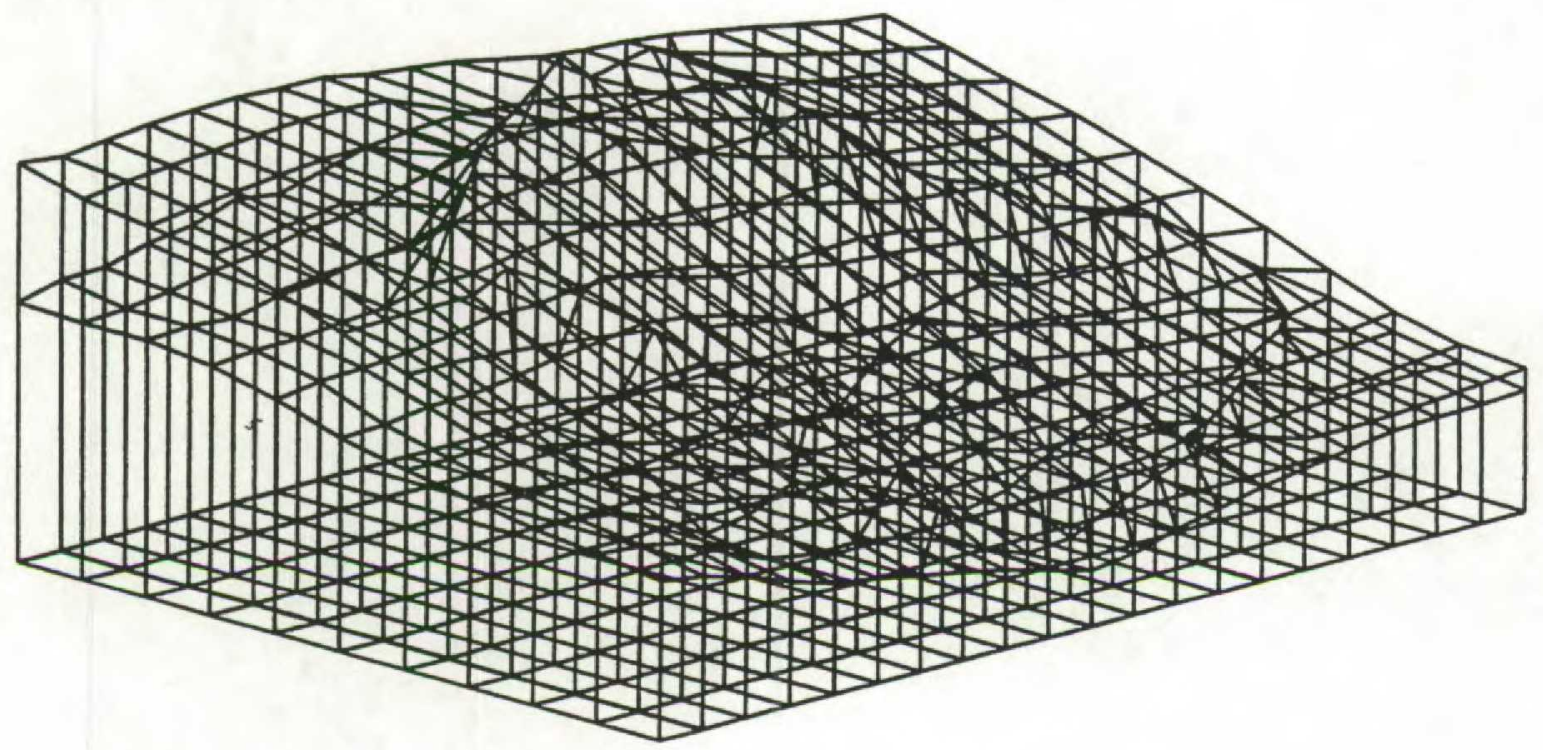

Figure 4. 3D-FE net
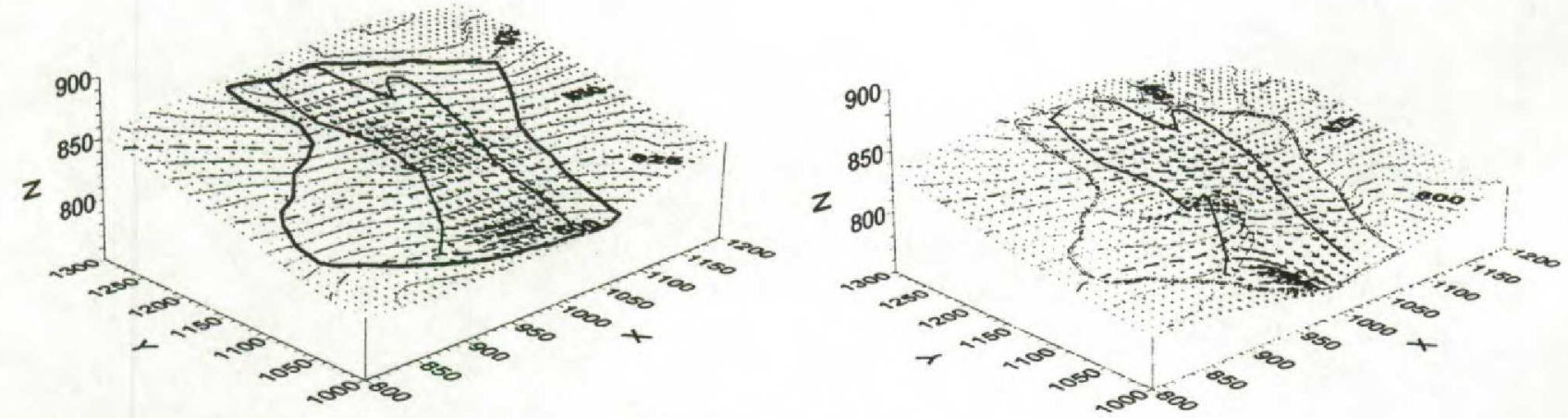

Figure 5. FE-model results (surface and sliding surface) 